\title{
Low field dedicated magnetic resonance imaging in untreated rheumatoid arthritis of recent onset
}

\author{
H Lindegaard, J Vallø, K Hørslev-Petersen, P Junker, M Østergaard
}

\begin{abstract}
Objective-To compare a low field dedicated extremity magnetic resonance imaging system (E-MRI) with $x$ ray and clinical examination, in the detection of inflammation and erosive lesions in wrist and metacarpophalangeal (MCP) joints in newly diagnosed, untreated rheumatoid arthritis (RA).

Patients and methods-Twenty five patients (disease duration $\leqslant 1$ year) and three healthy controls entered the study. An $x$ ray examination and MRI (before and after intravenous injection of a contrast agent) of the 2nd-5th MCP joints and the wrist was performed. The number of erosions on $x$ ray examination and MRI was calculated, and synovitis in the MCP joints and wrists was graded semiquantitatively.

Results-E-MRI detected 57 bone erosions, whereas only six erosions were disclosed by $x$ ray examination (ratio 9.5:1). Synovial hypertrophy grades were significantly higher in RA joints with clinical signs of joint inflammation-that is, swelling and/or tenderness (median 3, 5th-95th centile 1-4) than without these clinical signs (median 2 , 5th-95th centile $1-3), p<0.001 .51 \%$ of the joints without
\end{abstract}

Department of

Internal Medicine C, Section of

Rheumatology, Odense

University, Denmark

$\mathrm{H}$ Lindegaard

P Junker

Department of Radiology, Sønderborg Hospital

J Vallø

Graasten Gigthospital K Hørslev-Petersen

The Danish Research Centre of Magnetic

Resonance, H:S

Hvidovre Hospital,

University of

Copenhagen, Denmark

M Østergaard

Correspondence to: Dr H Lindegaard, Department of Internal Medicine, Section of Rheumatology, Odense University Hospital, Søndre Boulevard 29, Dk-5000 Odense C, Denmark lindegaard@dadlnet.dk

Accepted 15 November 2000

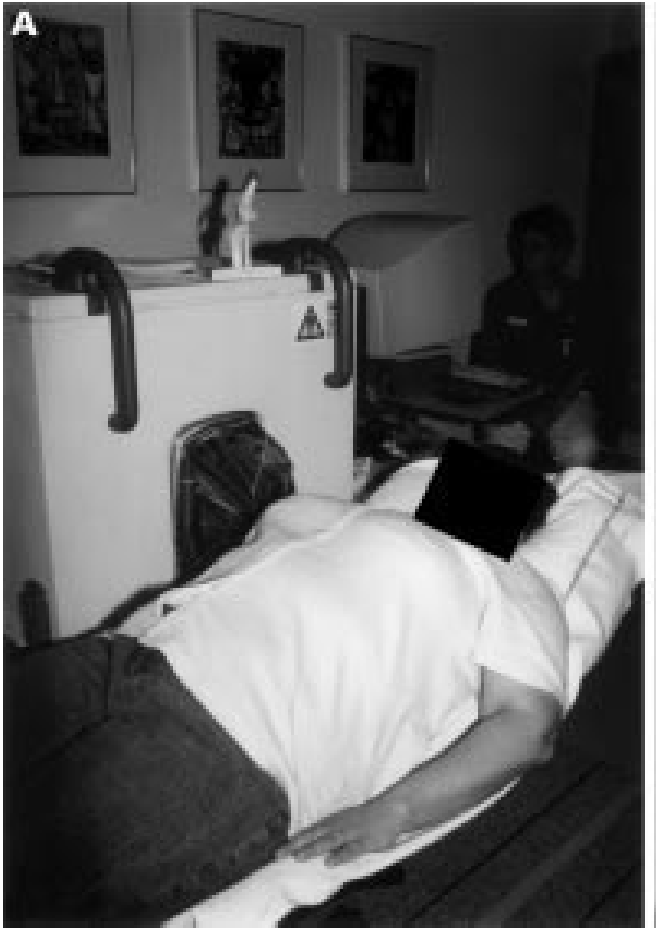

clinical signs of synovitis showed synovial hypertrophy on E-MRI. There was a positive correlation between MRI scores of synovitis and the number of erosions detected by MRI in the MCP joints (Spearman $\left.r_{\mathrm{s}}=0.31, \mathrm{p}<0.01\right)$. No healthy controls had erosions or synovitis on MRI. Conclusion-Joint destruction starts very early in RA and E-MRI allows detailed evaluation of inflammatory and destructive changes in wrists and MCP joints in patients with incipient RA.

(Ann Rheum Dis 2001;60:770-776)

Rheumatoid arthritis (RA) is a chronic inflammatory joint disease, characterised by frequent and early involvement of wrists, metacarpophalangeal (MCP) and proximal interphalangeal joints. ${ }^{1}$

The diagnosis is often difficult, not least at an early stage, and the disease course is difficult to predict in individual patients. Recent data suggest that early and aggressive treatment is better than the more conservative strategies used previously. ${ }^{2-4}$ This implies a need for development of methods which can better distinguish between patient subsets at high risk of developing erosive disease and patients with a more favourable prognosis. An $x$ ray examination is

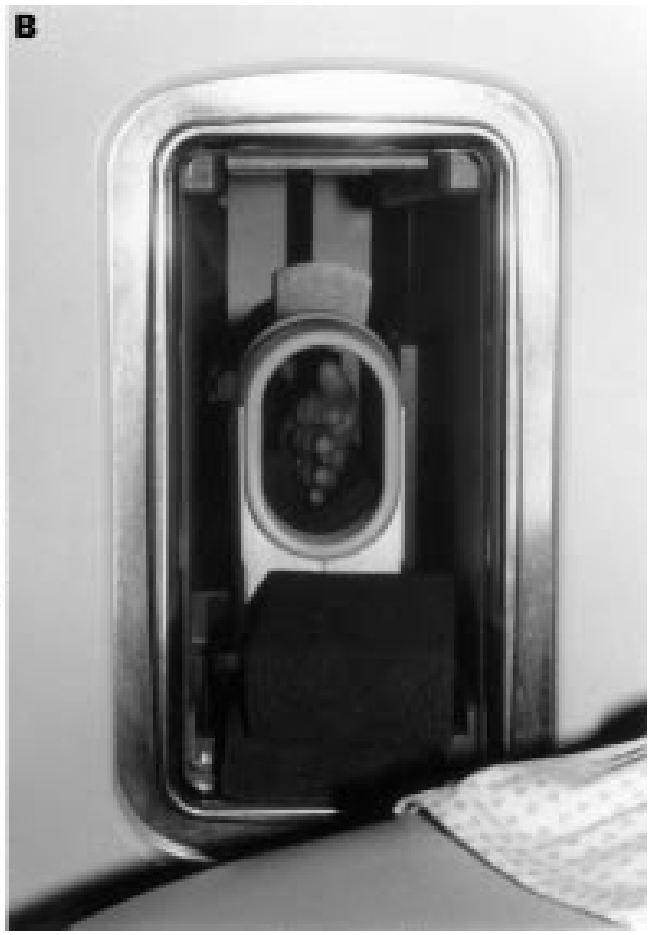

Figure 1 (A) Patient positioning for extremity magnetic resonance imaging. (B) Hand with extended fingers placed in the coil. To avoid movements the hand was fixed by foam rubber pillows. 
well established in the assessment of disease severity but does not reflect current inflammatory activity. Thus joint $x$ ray examination depicts lesions which have arisen as a result of past inflammatory processes, but is of limited value in detecting early structural damage. ${ }^{5}$ Within recent years, magnetic resonance imaging (MRI) has been shown to be better than clinical and $x$ ray examinations for the identification of inflammatory and destructive processes in RA joints. ${ }^{6-8}$ Furthermore, preliminary studies suggest a role for MRI as prognostic indicator in early RA. ${ }^{9}{ }^{10}$ However, most previous studies have been performed by using high field, whole body MR units. Less expensive, more comfortable and more convenient alternatives are desirable. This study reports the results of MRI performed on rheumatoid wrist and finger joints by a low field dedicated MRI system specifically designed for the examination of peripheral joints and limbs.

\section{Patients and methods}

PATIENTS

Twenty five consecutive patients with rheumatoid arthritis of less than 12 months' duration were recruited from the Early Synovitis Clinic in South Jutland, Denmark. All patients fulfilled the ACR (American College of Rheumatology) 1987 revised criteria. ${ }^{11}$ Their median age was 55 years (range 20-69). The female/male ratio was $18 / 7$. The median disease duration since the onset of joint symptoms was 122 days (range 55-360). Twenty four patients were seropositive for IgM rheumatoid factor. None of the patients had received corticosteroids or disease modifying antirheumatic drugs before inclusion in the study. The study was conducted in accordance with the Declaration of Helsinki, and local ethics committee approval was obtained before starting the study (J No 19980024).

CONTROLS

Three healthy controls (one woman, two men) without clinical evidence of arthritis were recruited from among the hospital staff. Their median age was 46 years (range $34-55$ ).

\section{CLINICAL EXAMINATION}

All clinical examinations were done by the same rheumatologist. The examinations included assessments of joint swelling and joint tenderness, as suggested by EULAR. ${ }^{12}$ Clinical synovitis in a joint was considered in the presence of joint swelling or tenderness, or both.

\section{EXTREMITY MRI}

MRI of the wrist and 2nd-5th MCP joints was performed by a $0.2 \mathrm{~T}$ Artoscan system (ESAOTE Biomedica, Italy). The patients were comfortably seated in an adjustable scanning chair with the dominant hand positioned
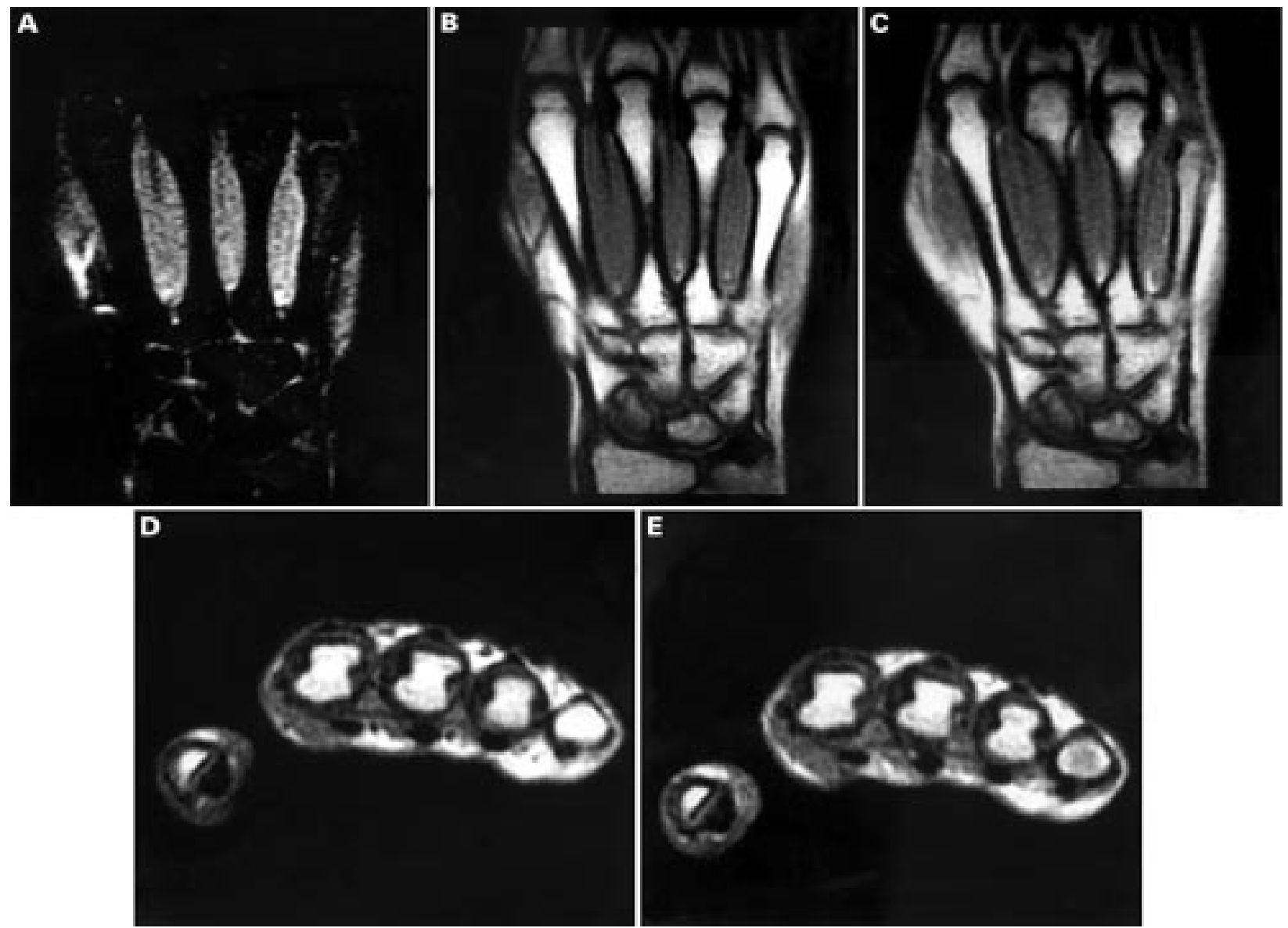

Figure 2 Healthy control. Magnetic resonance images of wrist and metacarpophalangeal (MCP) joints. No synovitis or erosions. $(A-C)$ Coronal STIR-image (A) and coronal $T$, weighted spin echo images before (B) and after $(C)$ IV gadodiamide. (D, E) Transversal $T$, weighted spin echo images of the MCP joints before (D) and after (E) IV gadodiamide. No intra-articular areas with high signal intensity (bright) on STIR or after IV contrast are seen. Thus no signs of synovitis are found. 
in the magnet in neutral rotation with the thumb up and the fingers extended (fig 1) The imaging protocol comprised a coronal short $\mathrm{T}_{1}$ inversion recovery (STIR) sequence, followed by coronal and axial $T_{1}$ weighted spin echo images obtained before and after intravenous (IV) injection of gadodiamide (Omniscan, Nycomed Amersham), $0.1 \mathrm{mmol} / \mathrm{kg}$ body weight, through a peripheral vein. The postcontrast coronal and axial images were started three minutes after the injection of gadodiamide. The imaging parameters for the STIR sequence were as follows: repetition time (TR) $500 \mathrm{~ms}$, echo time (TE) $18 \mathrm{~ms}$, matrix size 256 $\times 160$, field of view (FOV) $200 \mathrm{~mm}$, slice thickness $3 \mathrm{~mm}$, and distance factor 0.1 . For the $T_{1}$ weighted spin echo sequences the imaging parameters were as follows: TR $500 \mathrm{~ms}$, TE 18 ms, matrix size $256 \times 192$, FOV $200 \mathrm{~mm}$, slice thickness $3 \mathrm{~mm}$, and distance factor 0.1 . Owing to the small magnet size the true FOV of the coronal images was $120 \mathrm{~mm}$. The approximate imaging time in each patient was 45 minutes.

The MR images were all scored by a rheumatologist experienced in reading $M R$ images of the RA joints, who was unaware of the clinical and radiographic findings. Synovitis in the MCP joints and wrists was graded semiquantitatively from 0 to 4 as described by Klarlund et $a l{ }^{13}$ by comparing pre- and post-contrast axial and coronal $T_{1}$ weighted spin echo images (figs 2 and 3 ). The scale was defined as follows: grade $0=$ no visible enhancement; grade 1 = slight enhancement; grade $2=$ marked enhancement of small areas; grade $3=$ marked enhancement of moderate sized areas; grade $4=$ marked enhancement of large areas. Grades $0-1$ were considered as normal and grades $2-4$ as pathological. An MRI score of MCP joint synovial membrane hypertrophy was calculated by summing the scores of the 2nd-5th MCP joints. On $\mathrm{T}_{1}$ weighted $M R$ images before gadodiamide injection, bone erosions were identified by the focal loss of normal low signal intensity from cortical bone and the higher signal from trabecular bone, in combination with correct anatomical localisation (fig 4). A marked increase in the signal intensity of the erosion after IV injection of gadodiamide indicates the presence of inflamed synovial tissue in the erosion. ${ }^{13}$ To be accepted the bone erosions had to be visible on both axial and coronal sections. The MCP joint was divided into four quadrants, and in the wrist the bases of the metacarpal and the carpal joints were assessed for the presence or absence of bone erosions. The 1st MCP joint was not included because only axial images were available for this joint. In most cases it was not possible to obtain adequate images of the radius and ulna because the FOV of the MRI system was too small. Therefore, the erosions in these two bones were omitted from MRI and radiological scoring.
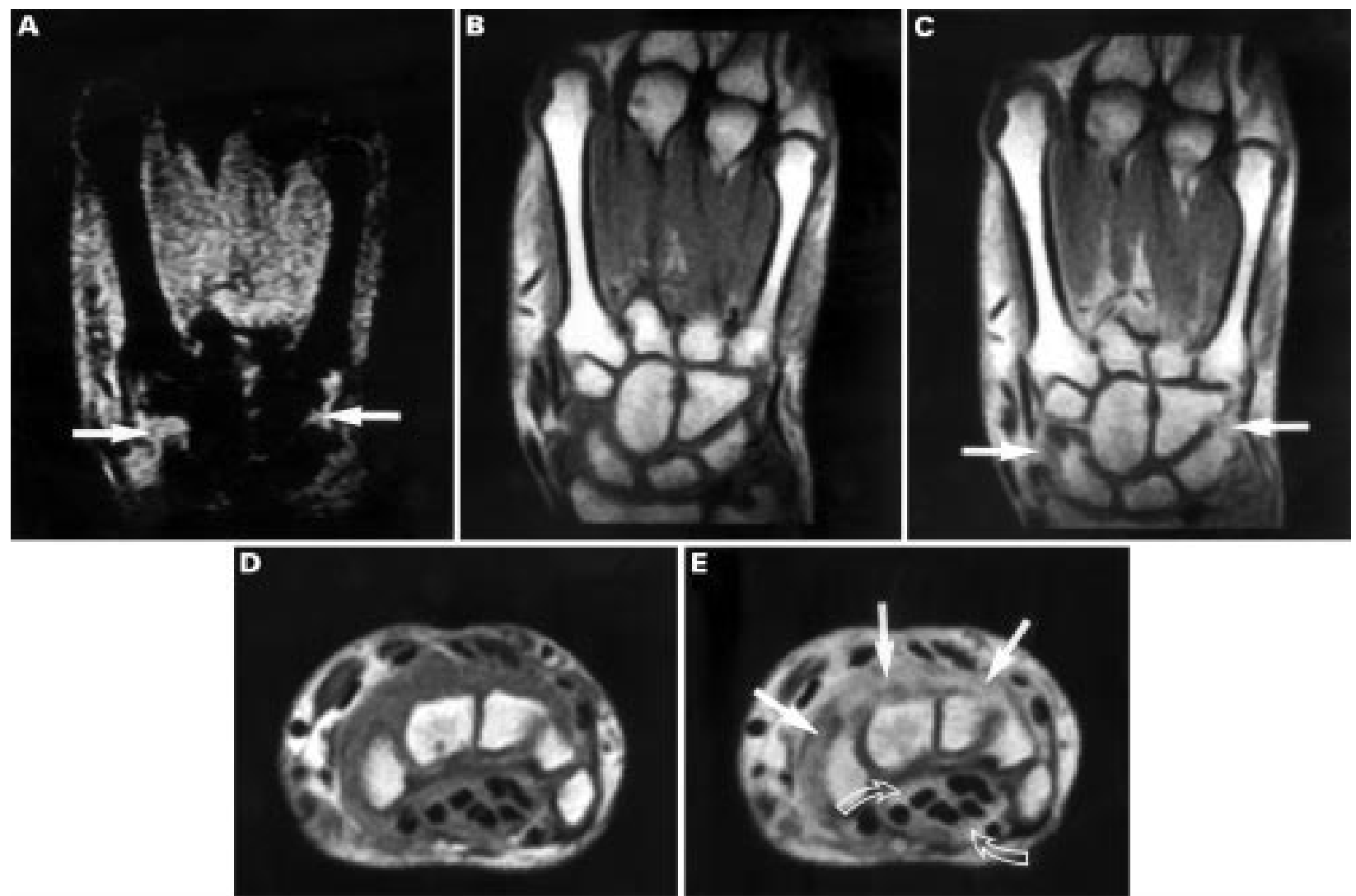

Figure 3 Patient with rheumatoid arthritis. Magnetic resonance images of wrist and metacarpophalangeal (MCP) joints show synovitis in the wrist joint and tenosynovitis. $(A-C)$ Coronal STIR image $(A)$ and coronal $T_{1}$ weighted spin echo images before $(B)$ and after $(C)$ IV gadodiamide. (D, E) Transversal $T$, weighted spin echo images of the wrist before (D) and after $(E)$ IV gadodiamide. In the wrist joint, areas with high signal intensity (bright) on STIR and after IV contrast are seen corresponding to the synovium (grade 4-that is, synovitis, straight arrows) as well as around the flexor tendons (tenosynovitis, curved arrows). No signs of synovitis are seen in the 2nd-5th MCP joints. 
$X$ RAY EXAMINATION

Radiographs of the wrist and hand in the anteroposterior and Nørgaard projection were obtained before MRI. A single coated mammography film (MRF 31 Du-Med, Herning, Denmark) was used.

A second observer, a musculoskeletal radiologist who was unaware of the MRI and clinical findings, evaluated all the radiographs for the presence and number of bony erosions in the four MCP quadrants of the MCP joints described above - the bases of the metacarpal joints, the carpal bones, distal radius, and ulna.

LABORATORY ANALYSES

Serum C reactive protein (CRP), erythrocyte sedimentation rate (ESR), and IgM rheumatoid factor were measured by standard methods.

STATISTICAL ANALYSIS

Intervals for synovial hypertrophy grades were expressed as medians and 5th and 95th centiles. In analyses including more than two groups the Kruskal-Wallis equality of populations rank test was employed. When the Kruskal-Wallis test was significant $(p<0.05)$, the Mann-Whitney $U$ test was used for pairwise group comparison. Correlations were assessed by Spearman's test of rank correlation. Values $\mathrm{p}<0.05$ by a two tailed test were considered to be significant.
Table 1 Number of erosions detected by extremity magnetic resonance imaging (E-MRI) and $x$ ray examination in wrists and metacarpophalangeal (MCP) joint quadrants

\begin{tabular}{llc}
\hline & \multicolumn{2}{l}{$\begin{array}{l}\text { Erosions on } x \text { ray } \\
(n=300 \text { bones })\end{array}$} \\
\cline { 2 - 3 } Wrist bones & - & + \\
\hline Erosions on E-MRI (n=300 bones) & & \\
- & 266 & 0 \\
+ & 34 & 34 \\
& \multicolumn{2}{l}{ Erosions on $x$ ray } \\
MCP joint quadrants & $-(n=400$ quadrants $)$ \\
Erosions on E-MRI (n=400 quadrants) & + \\
- & 376 & 1 \\
+ & 18 & 5 \\
\hline
\end{tabular}

\section{Results}

BONE EROSIONS

Extremity MRI (E-MRI) and $x$ ray studies were made of a total of 300 wrist bones and 400 quadrants in MCP joints, corresponding to 200 single bones. In the wrist, E-MRI detected 34 single bones with erosions, whereas none were detected by $x$ ray examination (table 1). Similarly, E-MRI of MCP joints showed bone erosions in 23 quadrants (18 patients), while erosions were detected in only six quadrants (four patients) by $x$ ray examination (table 1 ). The resulting MRI to $x$ ray erosion detection ratio was 9.5:1. One radiographic erosion was not detected by MRI. One healthy control had a large intraosseous subchondral cyst with a clearly defined border, but no erosions were observed
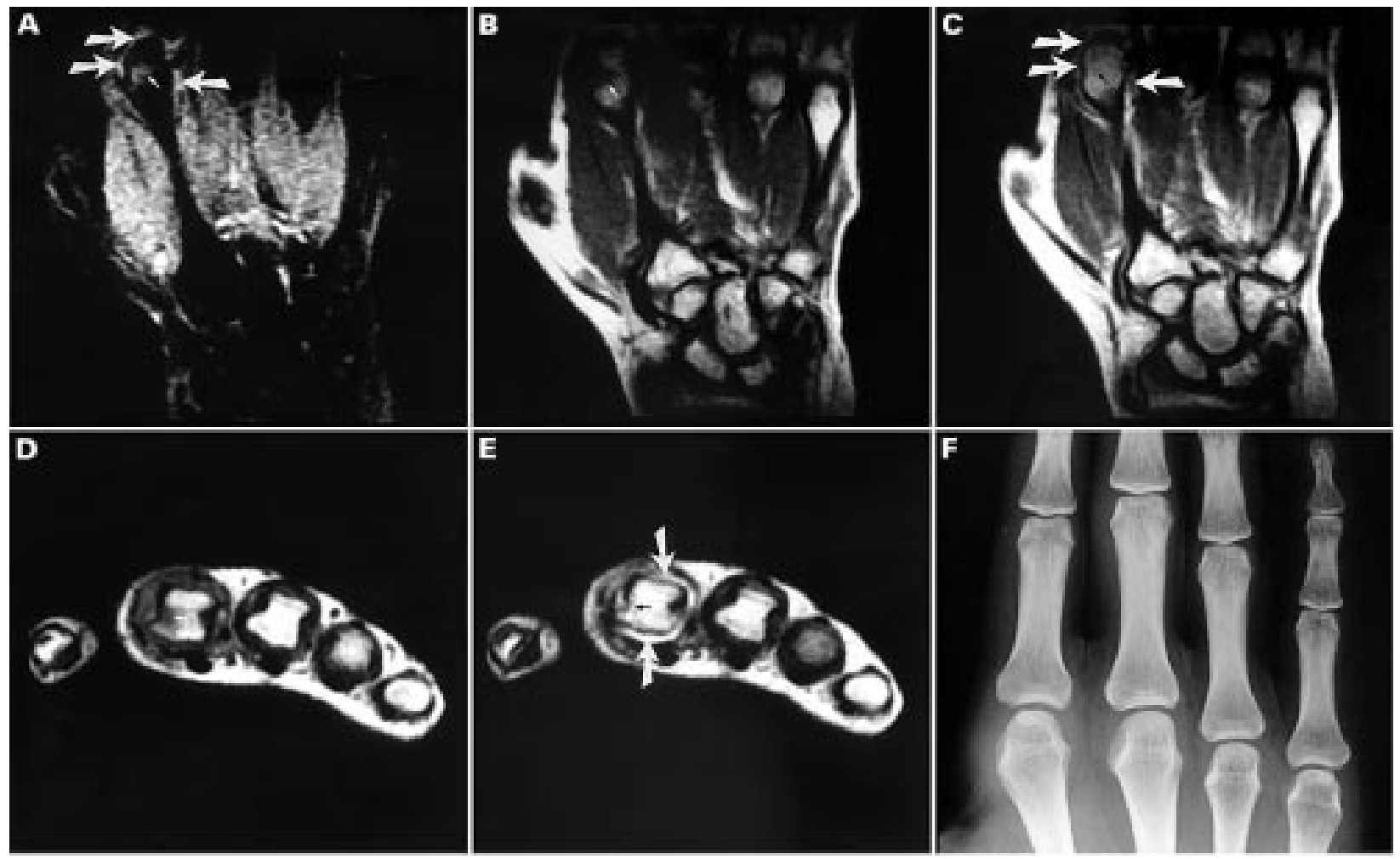

Figure 4 Patient with rheumatoid arthritis. Magnetic resonance images and $x$ ray picture of the wrist and metacarpophalangeal (MCP) joints show synovitis and bone erosion in the $2 n d$ MCP joint. $(A-C)$ Coronal STIR image $(A)$ and coronal $T_{1}$ weighted spin echo images before (B) and after (C) IV gadodiamide. (D, E) Transversal $T_{1}$ weighted spin echo images before (D) and after (E) IV gadodiamide. In the 2 nd MCP joint, areas with high signal intensity (bright) on STIR and after IV contrast are seen corresponding to the synovium (grade 4 - that is, synovitis, large white arrows) as well as in the bone (bone erosion, small black arrow). No signs of synovitis are seen in the 3rd-5th MCP joints. Mild, grade 2 synovial membrane hypertrophy was found in the wrist, but is not properly visualised in the presented slice. (F) Conventional $x$ ray in the anteroposterior projection. The erosion in the $2 n d$ metacarpal head is not seen. 
Table 2 Synovitis, as assessed clinically and by magnetic resonance imaging (MRI)

\begin{tabular}{lll}
\hline & \multicolumn{2}{l}{$\begin{array}{l}\text { Clinical synovitis } \\
(n=125 \text { joints })\end{array}$} \\
\cline { 2 - 3 } & - & + \\
\hline MRI synovial hypertrophy (n=125 joints) & 41 & 5 \\
Grades 0-1 & 43 & 36 \\
Grades 2-4 & & \\
\hline
\end{tabular}

Synovial hypertrophy grades were significantly higher in joints with clinical signs of synovitis $(\mathrm{p}<0.001) .51 \%$ of the joints without clinical findings of synovitis had demonstrable synovial hypertrophy - that is, the extremity MRI is more sensitive than clinical investigation.

There was a positive correlation between MRI scores of synovitis and the number of erosions detected by MRI when MCP and wrist joints were analysed together (Spearman's $\left.r_{\mathrm{s}}=0.39, \mathrm{p}<0.001\right)$. A similar positive correlation was observed in MCP joints $\left(r_{\mathrm{s}}=0.31, \mathrm{p}<0.01\right)$ but not in wrists alone.

\section{SYNOVIAL MEMBRANE HYPERTROPHY}

In rheumatoid MCP joints, synovial membrane hypertrophy grades ranged from 0 to 4 (median 2, 5th-95th centile 0-3), whereas all healthy controls were assigned grades 0 or 1 (median 0, 5th-95th centile $0-1$ ). The sum of grades from the 2 nd to the 5 th MCP joints was significantly higher in patients than controls $(\mathrm{p}<0.001)$. In RA wrists the synovial membrane hypertrophy grades range was 0-4 (median 3, 5th-95th centile 1-4) and in healthy controls grades were 0 or 1 (median 0 , 5 th-95th centile $0-1), p<0.01$. MRI synovitis, defined as marked post-gadodiamide signal increase in the synovium (grades 2-4), was found in 79 joints, while clinical synovitis (joint swelling and/or tenderness) was diagnosed in 41 joints. Five MCP joints with clinical synovitis did not show MRI synovitis. Table 2 shows that synovial hypertrophy grades were significantly higher in RA joints with clinical signs of joint inflammation (median 3, 5th-95th centile 1-4) than in joints without swelling and/or tenderness (median 2, 5th-95th centile 1-3), $\mathrm{p}<0.001$. Fifty one per cent $(43 / 84)$ of the joints without clinical soft tissue swelling or effusion showed synovial hypertrophy on E-MRI. In five joints with clinical signs of inflammation no synovial membrane hypertrophy could be shown on E-MRI.

A significant positive correlation was found between synovial membrane hypertrophy in the wrist and CRP (Spearman $r_{\mathrm{s}}=0.40$, $\mathrm{p}<0.05)$. The score of the MCP joint synovial hypertrophy (sum of grades from the 2 nd to the 5th MCP joint) did not correlate with CRP, $\mathrm{ESR}$, or disease duration.

\section{Discussion}

There is accumulating evidence, that MRI is more sensitive in identifying joint abnormalities than clinical and conventional $x$ ray examination..$^{6-9}$ 13-17 However, most previous MRI studies have focused on patients with long disease duration and large joints, knee joints in particular. In addition, they have all been performed using high field, whole body MRI units.
In our study a low field MRI unit dedicated to extremity imaging was used to obtain MR images of the hands in an untreated cohort with early disease. Our study showed, that $x$ ray examination only disclosed about $10-15 \%$ of the erosions visible on MRI. This figure accords well with previous studies comparing MRI with $x$ ray findings in RA joints of different sizes..$^{6-9} 131418$ It should be emphasised, however, that the exact accuracy of MRI detection of erosions and synovitis has not been verified, in this or earlier studies. The E-MRI unit has several advantages compared with whole body units. Firstly, costs are considerably lower; secondly, patients can be positioned more comfortably; and thirdly, claustrophobia, a major problem in whole body units, is totally avoided. $^{19}{ }^{20}$ The disadvantages of E-MRI include smaller field of view-that is, fewer joints can be examined in one session, the longer imaging time implying a risk of more patient movement and blurred imaging. However, these latter drawbacks may be partially avoided by better immobilisation due to more comfortable positioning. Moreover, the E-MRI technique is limited by a lower spatial resolution and a reduced number of possible imaging techniques compared with whole body units. In particular, spectral fat saturation cannot be achieved owing to the low field strength. This technique allows improved visualisation of bone marrow oedema, which has been proposed as an early sign of bone destruction. ${ }^{8} 15$ However, the exact significance of this finding remains to be settled, and further studies are needed to determine whether the STIR technique, which is possible by E-MRI, can provide equivalent information.

Previous MRI studies of patients with established RA have shown that the inflamed synovial membrane can be identified from the surrounding tissue and joint effusions and that synovial membrane volume and joint effusion can be measured in a fairly precise and reproducible manner in knees. ${ }^{21}{ }^{22}$ The present results on synovial grading in finger and wrist joints accord with previous studies on knee and finger joints showing that synovial membrane hypertrophy was significantly higher in joints with clinical signs of inflammation (swelling and/or tenderness) than in joints without these findings. ${ }^{162-25}$ However, in this cohort of patients with disease of recent onset, synovial hypertrophy could be shown in a considerable number of joints without clinical soft tissue swelling of the joints (51\%).

The relation between the synovitis grade and later development of joint deformity has not been settled. Most people with early RA are characterised by normal $x$ ray findings despite clinical involvement of the small joints in hands and fingers. Five of 25 patients presented with no clinical signs of synovitis in wrists or MCP joints and 20 had normal $x$ ray findings. In contrast, only one patient had no synovitis as estimated by post-gadodiamide signal increase in the synovium. There was a positive correlation between MRI scores of synovitis and the number of MRI erosions. These findings imply that the disease affects many joints at a very 
early stage, even in the absence of clinical signs of synovitis.

A positive correlation was found between wrist joint synovial hypertrophy and CRP. A similar correlation was not found for MCP joints. This discrepancy may reflect differences in synovial volumes between joints of different size, implying differences in release of proinflammatory cytokines to the circulation. ${ }^{17}$

Recent studies have suggested that MRI is an indicator of subsequent erosive progression. ${ }^{9}$ 26-28 A one year follow up study of wrists of 42 patients with early RA by McQueen, Huang, and coworkers indicated that baseline MRI findings may be of prognostic value for later joint destruction as synovitis, bone marrow oedema, and MRI erosions were related to new MRI erosions within the following year with odds ratios of 2.1, 6.5, and 13.8, respectively. ${ }^{26}{ }^{27}$ In addition, Østergaard et $a l,{ }^{9}$ found a close correlation between area under the curve synovial membrane volumes and the rate of erosive progression on MRI and $x$ ray examination in a one year follow up study of wrists in 26 patients with RA (Spearman $r_{\mathrm{s}}=0.69, \mathrm{p}<0.001$ ). In contrast, Klarlund et al, found no correlation between baseline MRI and erosive progression, but a very low progression rate in their cohort in combination with a relatively short follow up period may account for this discrepancy. ${ }^{28}$

Recently, a diagnostic value of MRI has been suggested by Sugimoto et $a l^{29}$, who found, that inclusion of MRI synovitis in the classification tree format of the ACR 1987 criteria for RA ${ }^{11}$ improved the sensitivity and specificity of these criteria.

The relation between MRI lesions and erosions detected by $x$ ray examination is under debate, ${ }^{30}$ in particular, whether MRI lesions will progress into an erosion demonstrable on $x$ ray examination. Five of six radiographic erosions in our study were visible at the same anatomical localisation using MRI. In addition the study has shown that even at a very early stage of the disease affected joints are targeted by destructive processes at multiple sites. Conceivably, these individual lesions will grow and ultimately fuse into erosions which can be detected by $x$ ray examination. Longitudinal studies are needed to clarify this issue.

Finally, it should be emphasised that the reproducibility (inter-/intra-reader agreement) of the MRI erosion and synovitis scores need to be assessed. Methodological work within this area has recently been started in an OMERACT MRI study group. ${ }^{31} 32$

In summary, dedicated low field E-MRI allowed detailed visualisation of inflammatory and destructive lesions in wrists with early RA and MCP joints. Follow up studies and comparisons with more advanced high field MRI units are needed, but the combination of lower costs, more comfortable patient positioning, and the promising preliminary results suggests a potential for the E-MRI technique in the evaluation of RA at an early stage.

We acknowledge the financial support by grants from the Danish Rheumatism Association and the Institute of Clinical Research, Odense University.
1 Fleming A, Crown JM, Corbett M. Early rheumatoid disease. I. Onset. Ann Rheum Dis 1976;35:357-60.

2 Breedveld FC. New perspectives on treating rheumatoid arthritis [editorial; comment]. N Engl J Med 1995;333: 183-4.

3 Emery P. Early rheumatoid arthritis: therapeutic strategies. Scand J Rheumatol Suppl 1994;100:3-7.

4 Emery P. Therapeutic approaches for early rheumatoid arthritis. How early? How aggressive? Br J Rheumatol 1995;34(suppl 2):87-90.

5 Matsuda Y, Yamanaka H, Higami K, Kashiwazaki S. Time lag between active joint inflammation and radiological progression in patients with early rheumatoid arthritis. J Rheugression in patients with

6 Forslind K, Larsson EM, Johansson A, Svensson B. Detection of joint pathology by magnetic resonance imaging in patients with early rheumatoid arthritis. Br J Rheumatol 1997;36:683-8.

7 Jorgensen C, Cyteval C, Anaya JM, Baron MP, Lamarque $\mathrm{JL}$, Sany J. Sensitivity of magnetic resonance imaging of the wrist in very early rheumatoid arthritis. Clin Exp Rheumatol 1993;11:163-8.

8 McQueen FM, Stewart N, Crabbe J, Robinson E, Yeoman $\mathrm{S}$, Tan PLJ, et al. Magnetic resonance imaging of the wrist in early rheumatoid arthritis reveals a high prevalence of erosions at four months after symptom onset. Ann Rheum Dis 1998;57:350-6.

9 Østergaard M, Hansen M, Stoltenberg M, Gideon P, Klarlund $M$, Jensen $\mathrm{KE}$, et al. Magnetic resonance imagingdetermined synovial membrane volume as a marker of disease activity and a predictor of progressive joint destruction in the wrists of patients with rheumatoid arthritis. Arthritis Rheum 1999;42:918-29.

10 Jevtic V, Watt I, Rozman B, Presetnik M, Logar D, Praprotnik S, et al. Prognostic value of contrast enhanced Gd-DTPA MRI for development of bone erosive changes in rheumatoid arthritis. Br J Rheumatol 1996;35(suppl 3):26-30.

11 Arnett FC, Edworthy SM, Bloch DA, Mcshane DJ, Fries JF, Cooper NS, et al. The American Rheumatism Association 1987 revised criteria for the classification of rheumatoid 1987 revised criteria for the classification

12 Scott DL, van Riel PL, Van der Heijde, Bencke AS (on behalf of the EULAR Standing Committee for International Clinical Studies including Therapeutic TrialsESCISIT (Chairman: PLCM van Riel). EULAR handbook of clinical assessments in rheumatoid arthritis. The Netherlands: Van Zuiden Communications, 2000.

13 Klarlund M, Østergaard M, Gideon P, Sørensen K, Henriksen $\mathrm{O}$, Lorenzen I. Wrist and finger joint $\mathrm{MR}$ imaging in rheumatoid arthritis. Acta Radiol 1999;40:400-9.

14 Foley ND, Stack JP, Ryan M, Redmond U, Barry C, Ennis $\mathrm{J}$, et al. Magnetic resonance imaging in the assessment of rheumatoid arthritis-a comparison with plain film radiographs. Br J Rheumatol 1991;30:101-6.

15 McGonagle D, Conaghan PG, O'Connor P, Gibbon W, Green M, Wakefield R, et al. The relationship between synovitis and bone changes in early untreated rheumatoid arthritis: a controlled magnetic resonance imaging study. Arthritis Rheum 1999;42:1706-11.

16 Østergaard M, Gideon P, Sørensen K, Hansen M, Stoltenberg $\mathrm{M}$, Henriksen $\mathrm{O}$, et al. Scoring of synovial membrane hypertrophy and bone erosions by MR imaging in clinically active and inactive rheumatoid arthritis of the wrist. Scand J Rheumatol 1995;24:212-18.

17 Emery P, Luqmani R. The validity of surrogate markers in rheumatic disease. Br J Rheumatol 1993;32(suppl 3):3-8.

18 Østergaard M, Stoltenberg M, Gideon P, Sørensen K, Henriksen $\mathrm{O}$, Lorenzen I. Changes in synovial membrane and joint effusion volumes after intraarticular methylprednisolone. Quantitative assessment of inflammatory and destructive changes in arthritis by MRI. J Rheumatol 1996; 23:1151-61

19 Passariello R, Mastantuono M, Satragno L. Magnetic resonance imaging of the extremities using dedicated equipment: diagnostic and economic considerations. Acad Radiol 1996;3(suppl 1):S141-4.

20 Peterfy CG, Roberts T, Genant HK. Dedicated extremity MR imaging. An emerging technology. Radiol Clin North Am 1997;35:1-20.

21 Østergaard M, Gideon P, Henriksen O, Lorenzen I. Synovial volume - a marker of disease severity in rheumatoid arthrivolume - a marker of disease severity in rheumatoid arthri-
tis? Quantification by MRI. Scand J Rheumatol 1994;23: 197-202.

22 Østergaard M, Stoltenberg M, Henriksen O, Lorenzen I. The accuracy of MRI-determined synovial membrane and joint effusion volumes in arthritis. A comparison of preand post-aspiration volumes. Scand J Rheumatol 1995;24: $305-11$

23 Klarlund M, Østergaard M, Lorenzen I. Finger joint synovitis in rheumatoid arthritis: quantitative assessment by magnetic resonance imaging. Rheumatology (Oxford) 1999;38: 66-72.

24 Østergaard M, Stoltenberg M, Løvgren-Nielsen P, Volck B, Jensen CH, Lorenzen I. Magnetic resonance imagingdetermined synovial membrane and joint effusion volumes in rheumatoid arthritis and osteoarthritis: comparison with the macroscopic and microscopic appearance of the the macroscopic and microscopic appearance

25 Østergaard M, Hansen M, Stoltenberg M, Lorenzen I. Quantitative assessment of the synovial membrane in the
rheumatoid wrist: an easily obtained MRI score reflects the synovial volume. Br J Rheumatol 1996;35:965-71. 
26 McQueen FM, Stewart N, Crabbe J, Robinson E, Yeoman $\mathrm{S}$, Tan PLJ, et al. Magnetic resonance imaging of the wrist in early rheumatoid arthritis reveals progression of erosions despite clinical improvement. Ann Rheum Dis 1999;58: 156-63.

27 Huang J, Stewart N, Crabbe J, Robinson E, McLean L, Yeoman S, et al. A 1-year follow-up study of dynamic magnetic resonance imaging in early rheumatoid arthritis reveals synovitis to be increased in shared-epitope patients and predictive of erosions at 1-year. Rheumatology (Oxford) 2000;39:407-416

28 Klarlund $\mathrm{M}$, Østergaard $\mathrm{M}$, Jensen KE, Lysgård J, Madsen JL, Skiødt $\mathrm{H}$, et al and the TIRA group. Magnetic resonance imaging, radiography, and scintigraphy of the finger joints: one year follow up of patients with early arthritis. Ann Rheum Dis 2000;59:521-8.
29 Sugimoto H, Takeda A, Masuyama J, Furuse M. Early-stage Sugimoto H, Takeda A, Masuyama J, Furuse M. Early-stage rheumatoid arthritis: diagnostic

30 Østergaard M. MRI bone erosions and MRI bone lesions in early rheumatoid arthritis [letter], with reply by McGonagle, Conaghan and Emery. Arthritis Rheum 2000;43:949-

31 Østergaard M, Klarlund M, Lassere M, Conaghan P, Peterfy $\mathrm{C}$, McQueen F, et al. Interreader agreement in the assessment of magnetic resonance images of rheumatoid arthritis wrist and finger joints-an international multicenter study. J Rheumatol (in press)

32 Conaghan P, Edmonds J, Emery P, Genant H, Gibbon W, Klarlund M, et al. MRI in rheumatoid arthritis: summary of OMERACT activities, current status \& future plans. J Rheumatol (in press).

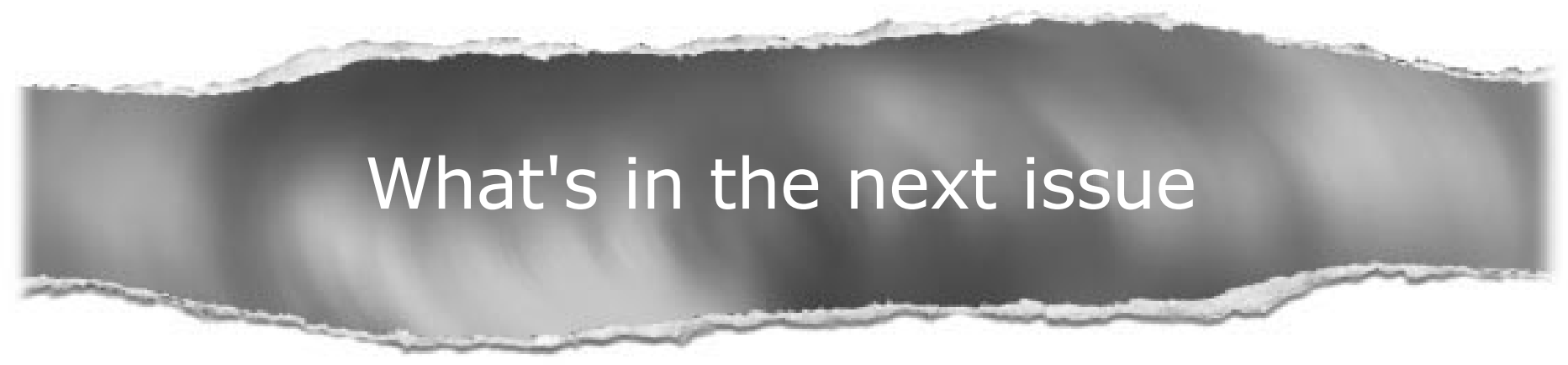

\section{Future content}

See which articles have just been accepted for publication and preview the table of contents for the next issue a month before it is published

\section{wWW.annrheumdis.com}

